\title{
TANF Participation and Intimate Partner Violence: Exploring Barriers to Self-Sufficiency
}

\author{
Johanna Thomas ${ }^{1}$, Shannon Collier-Tenison ${ }^{2}$, December Maxwell ${ }^{3} \&$ Cody Cheek $^{4}$ \\ ${ }^{1}$ Ph.D., LMSW, School of Social Work, University of Arkansas, Fayetteville, Arkansas, USA \\ ${ }^{2}$ Ph.D., School of Social Work, University of Arkansas at Little Rock, Arkansas, USA \\ ${ }^{3} \mathrm{MSW}$, School of Social Work, University of Texas at Arlington, Arlington, Texas, USA \\ ${ }^{4}$ MBA, University of Texas at Arlington, Arlington, Texas (Deceased), USA \\ Correspondence: Johanna Thomas, Ph.D., LMSW, School of Social Work, University of Arkansas, Fayetteville, \\ Arkansas 72701, USA.
}

Received: September 29, 2017

doi:10.11114/ijsss.v5i12.2749
Accepted: October 25, $2017 \quad$ Available online: October 31,2017

URL: https://doi.org/10.11114/ijsss.v5i12.2749

\begin{abstract}
Interpersonal Violence (IPV) is regarded as a primary barrier to employment for women in poverty. For recipients of Temporary Assistance to Needy Families (TANF), required to participate in work-related activities, experiences of IPV threatens the ability to meet work requirements, resulting in sanctions, if they do not have exemptions through a domestic violence option (DVO) wai ver. The purpose of the current study was to assess the effects of IPV on self-sufficiency in a sample of TANF participants. Data for the study were collected from a mail survey instrument sent to 2,000 randomly selected TANF recipients in one state in the U.S. Findings indicate the majority of the sample $(\mathrm{N}=525)$ was female (96\%), non-white (73\%), and single (86\%). One-third of respondents experienced IPV and $29 \%$ experienced IPV within the past year. Approximately half of the respondents sustained a physical injury and 29\% reported trouble working due to IPV. Non-parametric correlation analysis indicated those who reported IPV were less likely to be employed ( $\mathrm{p}<.002)$. Respondents reporting violence in the past year and were less likely to be self-sufficient $(\mathrm{p}=.01)$. Lastly, participants who experienced an injury from IPV were also significantly more likely to have trouble working ( $\mathrm{p}$ <.001). Although IPV is just one of many barriers to self-sufficiency for poor women, the lack of access to employment can have dire consequences for women reliant upon TANF benefits. This study indicates a need to further explore the linkages between IPV, access to employment, and other barriers to self-sufficiency.
\end{abstract}

Keywords: TANF, interpersonal violence, self-sufficiency, poverty

\section{Introduction}

Intimate partner violence is an issue that stretches across gender, race, and income lines. Historically, intimate partner violence has been shown to be a primary barrier to employment for women who are impoverished (Brownell, 1998; Butler, Corbett, Bond, \& Hastedt, 2008; Pilkinton, 2010). The National Center for Injury Prevention and Control (2003) estimates that women in the United States lose 8 million days of paid employment each year due to intimate partner violence. According to the U.S. Department of Justice (Catalano, 2013), aggravated assault accounts for almost $45 \%$ of the intimate partner violence experienced by women in the United States, with sexual assault and robbery each accounting for $27-28 \%$ of the remaining reports of violence. Women are more likely to be injured by an intimate partner than are men, with $13 \%$ of intimate partner victimizations resulting in serious injury for women as opposed to 5\% for men (Catalano, 2013).

Impoverished women who are experiencing interpersonal violence, or who are survivors of violence by an intimate partner, often turn to social service programs to prepare to leave abusive situations or as they transition to independent living with their children (Cheng, 2012). Women who are abused may "often "cycle" between living with abusive partners" and relying on cash assistance (Pilkinton, 2010, p. 1015). This is just one of the reasons that single mothers make up the majority of Temporary Assistance to Needy Families (TANF) caseloads for adult recipients (Falk, 2016). Eligibility for TANF dictates that adult recipients must be responsible for at least one minor child and meet the poverty threshold dictated by state regulations to receive monetary aid (Falk, 2016). In addition, recipients who utilize the service s 
of state TANF programs must also meet the employment requirements set by the state in which benefits are received. TANF recipients are also required to assist the state in the collection of child support from non-custodial parents (Cole, 2000). This may require paternity testing, disclosing the location of the non-custodial parent, and aiding in the collection of child support in other ways. Although states may elect to waive these requirements for victims of interpersonal violence, very few waivers are actually granted under the TANF Family Violence Option (Pompa, 2007).

The policies of the TANF program both help and hinder the progress of women who are attempting to escape interpersonal violence from an intimate partner. Current policies may have a number of unintended results. First, an abusive partner may not allow a woman to join the workforce, which may prevent her from meeting eligibility requirements for assistance. Second, in order to find and keep employment, women must find affordable childcare for their young children while out of the home. Lastly, an abusive partner may not only take a toll on the individual woman, but may also disrupt the place of business where she is employed, harassing other employees and customers. Given these factors, it is evident that women who are leaving an abusive relationship face a plethora of barriers to employment and self-sufficiency. The purpose of the current study is to explore the relationship between self-reported intimate partner violence and self-sufficiency among a sample of TANF recipients in one southern state.

\section{Review of the Literature}

The terms domestic violence (DV) and intimate partner violence (IPV) are often used interchangeably. Historically, the term domestic violence has referred to abuse that is perpetrated by the husband within a married, heterosexual relationship (Wallace, 2015). Further, although domestic violence has primarily been used to describe instances of abuse between two people in a romantic relationship, it can also refer to violence among people living in the same household, such as elder or child abuse (World Health Organization, 2012). Because of this, the term interpersonal violence has evolved to encompass behaviors that perpetrate physical and sexual violence, psychological abuse, and controlling behaviors against an intimate partner (World Health Organization, 2012). Therefore, this paper will use the term interpersonal violence to refer to violence perpetrated by an intimate partner.

The literature on the relationship between violence by an intimate partner and poverty is deep and wide reaching. Similarly, the lasting impact of interpersonal violence on both individuals and communities and the many ways in which this occurs is well documented. However, the research addressing the effects of intimate partner violence on perceived self-sufficiency among women who rely upon social services such as cash assistance is less well developed. Therefore, building on existing literature, this paper will focus on the barriers to self-sufficiency for TANF recipients who are in or who have recently exited from a relationship in which they were subjected to interpersonal violence. Additionally, a Multi-Systems Life Course Perspective (Murphy-Erby, Christy-McMullin, Stauss, \& Schriver, 2010) is utilized to holistically examine barriers to employment for survivors of interpersonal violence by an intimate partner.

\subsection{Lasting Effects of Interpersonal Violence}

Studies on the intergenerational transmission of violence indicate that exposure to interpersonal violence in the household during childhood can have lasting effects (Smith et al., 2011). Exposure to IPV in childhood has been shown to increase the likelihood of becoming a perpetrator of IPV, a victim of IPV, or both during early adulthood (Smith et al., 2011). Additionally, children who witness IPV are more likely to have increased instances of psychiatric disorders, alcohol abuse, and issues with anger expression in adulthood (Armour \& Sleath, 2014). Similarly, research on Adverse Childhood Experiences (ACE) investigates complex intersections of the effects of poverty, violence, and oppression in childhood on adult health (Cronholm et al., 2015). Higher ACE scores correlate strongly with higher instances of substance abuse, risky sexual behavior, and psychiatric morbidity (Cronholm et al., 2015). IPV cannot be isolated from the intersection of poverty and oppression and, while this violence may occur regardless of socioeconomic status, exposure to IPV during childhood contributes to higher ACE scores, which highlight a multitude of lasting negative impacts in adulthood (Cronholm et al., 2015).

The intergenerational transmission of violence affects both individuals and communities, often with lasting economic ramification for both systems. Since individuals who witness violence in their own homes have a higher likelihood of developing a mental health issue, communities where instances of interpersonal violence are more frequent experience a greater need for mental health intervention (Zinzow et al., 2009). These needs are exacerbated in poor communities where mental health resources are already scarce (Chun-Chung Chow, Jaffee, \& Snowden, 2003) and there is a higher prevalence of interpersonal violence. The accumulation of risk in these low resource areas contributes to a complex intersectionality of violence, crime, and oppression (Amour \& Sleath, 2014; Bonomi et al., 2007). Furthermore, interpersonal violence has a cyclical impact on the community, wherein witnessing IPV correlates with higher rates of both IPV offending or victimization, of physical and mental health issues that can be economically draining, and of poverty (Cheng, 2012). 


\subsection{Intimate Partner Violence and Barriers to TANF Participation}

For recipients of Temporary Assistance to Needy Families (TANF) who are required to participate in work-related activities, intimate partner violence can threaten their ability to meet work requirements and result in sanctions, particularly if they are not afforded exemptions to these requirements through a Family Violence Option (FVO). As discussed below, in some instances, TANF policy exacerbates the difficulty in finding and maintaining employment for women who are subject to interpersonal violence. While this is one of many barriers to self-sufficiency for women who are impoverished, the lack of access to employment can have dire consequences for women reliant upon TANF benefits.

\subsection{Child Support Enforcement}

IPV is intrinsically tied to welfare participation and participant outcomes (Cheng, 2012; Riger \& Staggs, 2004). TANF is often one of the main sources of income for women who are lacking education or job skills needed for sustainable employment, particularly for those who are exiting abusive relationships, and their children. Cooperation with child support enforcement has long been a condition of cash assistance program participation (Cancian, Meyer, \& Caspar, 2008). In many cases TANF recipients are required to provide the name of their children's non-custodial parent in order to continue receiving benefits, thus potentially increasing their level of risk and stress (Bowie \& Dopwell, 2013). For women with abusive partners, cooperating with child support enforcement may make them more vulnerable to continued abuse as it may provide the abuser access to their location or access to the children. Although states have the option of including a FVO, which allows for program requirement waivers when the recipient's safety is a concern, this option is underutilized either due to a lack of awareness or a lack of trust in the system (Postmus, 2004).

\subsection{Affordable Quality Childcare}

Another primary requirement of TANF participation is that participants must be employed, or seeking employment, at least 20 hours per week, thus creating a need for affordable, consistent, quality childcare. The lack of access to safe, quality childcare is a barrier that remains in place for many women, but more so for those who may fear violence towards their children from a partner (Kimmerling et al., 2009; Pearson, Griswold, \& Thoennes, 2001). For women who are abused by an intimate partner, excessive absences are often cited as a cause of unstable employment. Gaps in childcare further contribute to days missed at work (Kimmerling et al., 2009; Pearson, Griswold, \& Thoennes, 2001). The extant literature further shows that some IPV perpetrators purposely fail to fulfill childcare duties as a way to sabotage victim attempts at financial success and stability (Riger, Staggs, \& Schewe, 2004).

\subsection{Mental and Physical Health Issues}

Mental health issues are frequently cited as barriers to employment among individuals who experience IPV (Pearson, Griswold, \& Thoennes, 2001; Riger, Staggs, \& Schewe, 2004). Current research indicates that post-traumatic stress disorder (PTSD) symptoms, which arise from psychological violence (e.g., stalking, berating, controlling) in conjunction with physical and sexual violence, often influence employment stability among victims of IPV (Kimmerling et al., 2009; Riger, Staggs, \& Schewe, 2004; Cheng, 2012; Riger \& Staggs, 2004). Additionally, victims of IPV also have a higher likelihood of developing a major depressive disorder, even long after the IPV has occurred (Cheng, 2012; Riger, Staggs, $\&$ Schewe, 2004). Current research indicates that both PTSD and depressive symptoms often interfere with employment and are associated with higher levels of unemployment (Cheng, 2012; Riger \& Staggs, 2004).

For those who have experienced IPV, physical health issues are also cited as barriers to employment (Kimmerling et al., 2009; Riger, Stags, \& Schewe, 2004). Both acute injuries and chronic health conditions arise as a result of IPV and contribute to work absences (Cheng, 2012; Riger, Staggs, \& Sche we, 2004; Kimmerling et al., 2009). Research has also found that some victims of IPV have experienced employment termination due to an acute injury or chronic physical health condition resulting from ongoing abuse (Cheng, 2012; Kimmerling et al., 2009). Consequently, the same barriers to employment for women who experience IPV have also become barriers to successful participation in TANF programs. Women who experience IPV continue to accumulate risk factors that bar them from successfully taking control of their lives and finances and becoming truly self-sufficient.

\subsection{Self-Sufficiency as an Exiting Mechanism}

The relationship between financial status, economic stress, and intimate partner violence is well documented in the literature. Numerous studies indicate that increased intimate partner violence is associated with lower levels of financial security (Renzetti, 2009; Benson, Fox, DeMaris, \& Van Wyk, 2003; Benson, Wooldredge, Thistlethwaite, \& Fox, 2004). Not surprisingly, TANF recipients who are emotionally and physically abused by an intimate partner fare worse on a number of measures of self-sufficiency than do recipients who report no abuse (Wetterson et al., 2004). Self-sufficiency, as related to financial independence, is defined as "a process of developing psychological strength properties and a goal-oriented progression toward realistic financial outcomes" (Hong, Sheriff, \& Naeger, 2009, p.357). Self-sufficiency is often measured by employment or financial self-sufficiency in reference to victims of IPV. Howe ver, self-sufficiency is 
much broader than the aforementioned definition. Self-sufficiency also encompasses the ability to manage bills, understand financial forms, make financial decisions, the ability to coordinate child-care and schooling for dependent children, to understand pathways to upward mobility, and to understand and gain the self-worth needed to provide for oneself and one's family (Hong, Polanin, \& Pigott, 2012).

Studies indicate that women with a history of abuse do not differ significantly from women who have not experienced violence by an intimate partner in terms of current employment or desire for employment (Renzetti, 2009). However, women with a history of abuse are more likely to report absenteeism, arriving late for work (Wetterson et al., 2004), health issues (both psychological and physical) affecting ability to work (Bonomi et al., 2007), and difficulty maintaining employment (Goodman, Smyth, Borges, \& Singer, 2009). While the existing literature supports a correlation between the need for financial resources through welfare and experiencing interpersonal violence, few studies have considered a broader view of self-sufficiency with this population. Thus, this study aims to explore this gap in the literature through the perspective of low-income women who have been abused by an intimate partner. The current study examines the relationship between intimate partner violence and self-sufficiency among a sample of TANF participants in one southern state in the U.S. Both intimate partner violence and self-sufficiency were self-reported and left to be defined by the participant, an approach not often taken with this particular population.

\section{Theoretical Framework}

Interpersonal violence is the creation of complex intersections of personal experiences and perceptions, social systems, historical and generational challenges and oppression, and systemic sexism (Lindhorst \& Tajima, 2008). As such, investigating facets of success in programs like the TANF economic assistance program for those who have experienced, or are experiencing, IPV requires a theoretical framework that encompasses a broad range of influences. For this study, a Multi-Systems Life Course (MSLC) perspective is used because of the ability of the framework to address the individual and societal life course, including historical influences, systemic impacts, and cultural context regarding perceptions and experiences of the individual (Murphy-Erby et al., 2010). This multidimensional approach allows integration of the participant's worldview encompassing complex identities and experiences central to traditionally marginalized populations.

Approaching the creation of the survey instrument, data collection and data analysis through the MSLC framework allowed the examination of a broad range of barriers to success for participants in the state TANF economic assistance program. Within the MSLC framework self-sufficiency is viewed not just as financial freedom, but also the ability to live independently and to rely upon oneself and one's support network to meet basic needs. MSLC also extends to view the individual in their whole environment, including both support systems and a view of the barriers that may prevent TANF participation, cause sanctions, and prevent self-sufficiency for victims of intimate partner violence such as child support, violence and disruption by the abuser, and physical and mental health barriers (Tolman \& Raphael, 2000). The MSLC framework allows both researchers and practitioners to view the participants within larger social structures.

\section{Methods}

Data for this exploratory study were collected in 2012 through mailed surveys to both former and current participants of one Southern state's TANF financial assistance program (Note 1). The sampling population consisted of all non-duplicated cases from 2011 and $2012(\mathrm{~N}=8,605)$. From this population, a sample of 2,000 TANF participants was randomly selected to receive the survey via mail. Among those who were mailed the survey, $525(26 \%)$ participants returned the survey from the first mailing and are included in the analysis. The mail survey contained approximately 60 questions covering broad areas related to the participants' experience in the state TANF program, their physical and mental health, education and educational needs, current childcare and childcare needs, as well as experiences with interpersonal violence. Participants who completed and mailed the survey back were mailed a $\$ 20$ gift card in return.

The overarching research question guiding the current study was: Is there a relationship between self-reported intimate partner violence and self-defined self-sufficiency? Additional research questions guiding this study include:

1. What are the demographic characteristics of the sample of women who self-identified as having been a victim of intimate partner violence?

2. Is there a relationship between household income and self-sufficiency?

3. Do TANF participants view program participation as supportive of self-sufficiency?

\subsection{Sample}

Among the 2,000 surveys mailed, 525 (26.3\%) were returned on the first and only mailing, which is considered an acceptable response rate since the margin of error is approximately $+/-3.67 \%$ with a confidence interval of $95 \%$ (Dillman, Smyth, \& Christian, 2009). Contrary to the existing literature and the expectations based on the mobility of people in 
poverty, less than $6 \%$ of the mailed surveys were returned due to an inability to locate the recipient at the address on file with the TANF agency.

Among the total sample $(\mathrm{N}=525)$, the overwhelming majority was female $(n=505,96.2 \%)$, non-white $(n=383,73 \%)$, and reported their marital status as single ( $n=453,86 \%$; See Table 1). Participants ranged in age from 18-49 years with the average age being 27 . On average, participants had 2 children, with more than three quarters indicating they had two children or less $(n=379,72.2 \%)$. More than half of the participants reported having some college or a college degree $(n=$ $281,53.5 \%)$. Less than half of the participants $(n=206,40 \%)$ indicated the TANF program assisted them with securing employment that allowed them to be self-sufficient. However, the vast majority of respondents reported an annual household income of $\$ 5,000$ or less $(n=349,66.5 \%)$ and $98 \%$ reported an annual income under $\$ 20,000$. Just over one quarter of respondents $(n=142,27 \%)$ reported working full-time at the time of the survey.

Table 1. Demographic Characteristics of Survey Participants

\begin{tabular}{|c|c|c|c|}
\hline & $\mathrm{N}$ & $\%$ & \\
\hline \multicolumn{4}{|l|}{ Sex } \\
\hline Male & 17 & 3.2 & \\
\hline Female & 505 & 96.2 & \\
\hline \multicolumn{4}{|l|}{ Race } \\
\hline White & 134 & 25.5 & \\
\hline Non-White & 383 & 73 & \\
\hline \multicolumn{4}{|l|}{ Marital Status } \\
\hline Married & 63 & 12 & \\
\hline Single & 453 & 86.3 & \\
\hline \multicolumn{4}{|l|}{ Education Level } \\
\hline Less than High School & 55 & 10.5 & \\
\hline High School or Equivalent & 182 & 34.7 & \\
\hline College & 281 & 53.5 & \\
\hline \multicolumn{4}{|l|}{ Employment Status } \\
\hline Full-time & 142 & 27 & \\
\hline Part-time & 110 & 21 & \\
\hline Unemployed seeking & 221 & 42.1 & \\
\hline Unemployed not seeking & 32 & 6.1 & \\
\hline \multicolumn{4}{|l|}{ Household Income } \\
\hline Under $\$ 5,000$ & 349 & 66.5 & \\
\hline$\$ 5,001-\$ 19,999$ & 124 & 23.6 & \\
\hline$\$ 20,00$ and above & 29 & & \\
\hline \multicolumn{4}{|l|}{ Ever Sanctioned } \\
\hline Yes & 242 & 46.1 & \\
\hline No & 274 & 52.2 & \\
\hline \multicolumn{4}{|l|}{ Self-Sufficient } \\
\hline Yes & 206 & 39.2 & \\
\hline No & 303 & 57.7 & \\
\hline \multicolumn{4}{|l|}{ Physical Violence by Partner } \\
\hline Yes & 186 & 35.4 & \\
\hline \multirow[t]{2}{*}{ No } & 333 & 63.4 & \\
\hline & Range & $M$ & s.d. \\
\hline Age & $18-49$ & 27.11 & 6.78 \\
\hline Number of Children & $1-7$ & 2.04 & 1.14 \\
\hline
\end{tabular}

Among the 525 survey respondents, just over one-third $(n=186,35 \%)$ reported having experience with a partner who had been physically violent toward them. Among the 186 participants who indicated experiencing physical violence in a current or previous relationship, the vast majority were female $(n=184,98.9 \%)$, non-White $(n=112,60.2 \%)$, and single $(n=157,84.4 \%$; See Table 2). 
Table 2. Demographic Characteristics of Participants who Reported Interpersonal Violence

\begin{tabular}{|c|c|c|c|}
\hline & $\mathrm{N}$ & $\%$ & \\
\hline \multicolumn{4}{|l|}{ Sex } \\
\hline Male & 1 & 0.5 & \\
\hline Female & 184 & 98.9 & \\
\hline \multicolumn{4}{|l|}{ Race } \\
\hline White & 71 & 38.2 & \\
\hline Non-White & 112 & 60.2 & \\
\hline \multicolumn{4}{|l|}{ Marital Status } \\
\hline Married & 26 & 14 & \\
\hline Single & 157 & 84.4 & \\
\hline \multicolumn{4}{|l|}{ Education Level } \\
\hline Less than High School & 17 & 9.1 & \\
\hline High School or Equivalent & 57 & 30.6 & \\
\hline College & 111 & 59.7 & \\
\hline \multicolumn{4}{|l|}{ Employment Status } \\
\hline Full-time & 34 & 18.3 & \\
\hline Part-time & 44 & 23.7 & \\
\hline Unemployed seeking & 89 & 47.8 & \\
\hline Unemployed not seeking & 14 & 7.5 & \\
\hline \multicolumn{4}{|l|}{ Household Income } \\
\hline Under $\$ 5,000$ & 127 & 68.3 & \\
\hline$\$ 5,001-\$ 19,999$ & 45 & 24.2 & \\
\hline$\$ 20,00$ and above & 7 & 3.8 & \\
\hline \multicolumn{4}{|l|}{ Ever Sanctioned } \\
\hline Yes & 91 & 48.9 & \\
\hline No & 91 & 48.9 & \\
\hline \multicolumn{4}{|l|}{ Self-Sufficient } \\
\hline Yes & 66 & 35.5 & \\
\hline \multirow[t]{2}{*}{ No } & 116 & 62.4 & \\
\hline & Range & $M$ & s.d \\
\hline Age & $18-48$ & 27.98 & 6.57 \\
\hline Number of Children & $1-7$ & 2.17 & 1.11 \\
\hline
\end{tabular}

Among the respondents who reported experiencing violence in a relationship, 29\% ( $n=54)$ reported IPV within the past year. Nearly one-half $(n=90,48.4 \%)$ of respondents reported sustaining a physical injury and $29 \%(n=55)$ reported having trouble working due to intimate partner violence. Lastly, $19 \%(n=37)$ of respondents indicated they had been a perpetrator of physical violence in a current or previous relationship, but only $3.8 \%(n=7)$ reported being physically violent with a partner in the last year (See Table 3).

Table 3. Intimate Partner Violence Questions

\begin{tabular}{lll}
\hline & $\mathrm{N}$ & $\%$ \\
\hline Violence in Past Year & & \\
$\quad$ Yes & 54 & 29 \\
$\quad$ No & 132 & 71 \\
Trouble Working due to Violence & & \\
$\quad$ Yes & 55 & 29.6 \\
$\quad$ No & 109 & 58.6 \\
Ever Physically Injured & 90 & \\
$\quad$ Yes & 64 & 34.4 \\
$\quad$ No & & \\
Participant was Physically Violent & 37 & 19.9 \\
$\quad$ Yes & 148 & 79.6 \\
$\quad$ No & & \\
Participant Physically Violent in Past & & \\
Year & 7 & 3.8 \\
$\quad$ Yes & 116 & 62.4 \\
$\quad$ No & & \\
\hline
\end{tabular}

\subsection{Measures}

For the dependent variable, self-sufficiency was operationalized by the survey question: "Do you think the State TANF economic assistance program has assisted you in getting a job that provides enough income to support your family?" in which respondents answered either yes (1) or no (2). Independent variables included in the models were: Ever experienced intimate partner violence $(1=$ yes, $2=$ no); employment status $(1=$ full time, $2=$ part time, $3=$ unemployed seeking, $4=$ unemployed not seeking); age (in years); number of children; level of education ( $1=$ less than High School, $2=$ High School or equivalent, $3=$ Some College $/$ College $)$; ever been sanctioned in the program $(1=$ yes, $2=$ no); and 
current household income ( $1=$ under $\$ 5,000,2=\$ 5,001-\$ 19,999,3=\$ 20,000$ and above $)$.

In addition to demographic characteristics a set of five self-report questions were asked if the respondent indicated that they had ever been in a relationship in which they experienced intimate partner violence. These variables include: Experienced violence in the past year $(1=$ yes, $2=$ no $)$, trouble working due to intimate partner violence $(1=$ yes, $2=$ no $)$, any violence by the respondent toward an intimate partner $(1=$ yes, $2=$ no), and violence by the respondent toward an intimate partner in the past year $(1=$ yes, $2=$ no $)$.

\subsection{Data Analysis}

Because the dependent and independent variables were both collected at the nominal level, uni variate and non-parametric analyses were employed to answer both the overarching research questions and the sub research questions. A series of frequencies, cross tabulations and chi-square analyses were constructed and examined first. Next, non-parametric Spearman's Rho correlation models were constructed, employed and examined.

Several chi-square analyses were used to assess the relationship between demographic characteristics and self-reported intimate partner violence. The only significant association found was between race and physical violence. Findings indicated that significantly more white respondents than non-white respondents reported experiencing physical violence than expected $\left(\mathrm{F}_{0}=47, \mathrm{~F}_{\mathrm{e}}=71 ; \chi^{2}=24.149, p .=.00\right)$. The only other significant associations were between employment and intimate partner violence and violence in the past year and self-sufficiency. As such, significantly fewer respondents who had a partner who was physically violent were employed full time as compared to their counterparts who had not experienced physical violence $\left(\mathrm{F}_{0}=34, \mathrm{~F}_{\mathrm{e}}=51 ; \chi^{2}=14.44, p=.006\right)$. For respondents who had experienced violence in the past year, significantly more than expected $\left(\mathrm{F}_{0}=42, \mathrm{~F}_{\mathrm{e}}=33 ; \chi^{2}=6.48, p=.01\right)$ indicated that the State TANF economic assistance program had not assisted them with becoming self-sufficient.

Correlational analyses, specifically Spearman's Rho, were used to further explore the relationship between intimate partner violence and the main demographic characteristics of participants (See Table 4). Findings from the correlational analysis indicate that there was a weak, negative, and significant correlation between physical violence by an intimate partner and employment status $\left(\mathrm{r}_{s}=-.137, p=.002\right)$, indicating that respondents who reported experiencing physical violence were less likely to be employed full-time than respondents who did not report experiencing violence. Moreover, non-parametric correlation analyses also found negative, significant correlations between a respondent's experience of

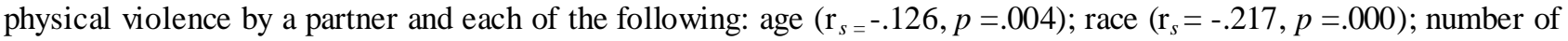
children $\left(\mathrm{r}_{s}=-.118, p=.010\right)$, and level of education $\left(\mathrm{r}_{s}=-.090, p=.042\right)$. There was a weak, negative and significant correlation between experiencing violence and age, indicating that younger women were more likely to report being victims of intimate partner violence. Correlational analyses confirmed the chi-square association between self-reporting intimate partner violence and race. As such, there was a moderate, negative and significant correlation between IPV and race, indicating that white women were more likely to self-report intimate partner violence. Findings also indicated that there was a negative, weak and significant correlation between self-report of intimate partner violence and having with fewer children $(\mu=2)$. Lastly, there was a negative, weak and significant correlation between self-reporting intimate partner violence and level of education. In sum, women who reported physical violence by an intimate partner were less likely to be employed, were younger, had fewer children, and reported lower levels of education.

Table 4. Correlation Matrix with Self-Sufficiency as the Dependent Variable

\begin{tabular}{|c|c|c|c|c|c|c|c|c|c|}
\hline & 1 & 2 & 3 & 4 & 5 & 6 & 7 & 8 & 9 \\
\hline 1. & 1 & & & & & & & & \\
\hline Self-Sufficiency & & & & & & & & & \\
\hline $\begin{array}{l}\text { 2. Intimate } \\
\text { Partner Violence }\end{array}$ & -.065 & 1 & & & & & & & \\
\hline $\begin{array}{l}\text { 3. Employment } \\
\text { Status }\end{array}$ & $.297 * *$ & $-.137 * *$ & 1 & & & & & & \\
\hline 4. Sanction & -.076 & .048 & $-.157^{* *}$ & 1 & & & & & \\
\hline 5. Age & -.003 & -.126 & $-.127 * *$ & $.152 * *$ & 1 & & & & \\
\hline 6. Race & .040 & $-.217 *$ & $.118 * *$ & .019 & $.193 * *$ & 1 & & & \\
\hline 7. \# of Children & .008 & $-.113 *$ & -.015 & -.064 & $.402 * *$ & $.086^{*}$ & 1 & & \\
\hline 8. Education & .029 & $-.090 *$ & -.066 & .082 & $.226 * *$ & -.058 & -.075 & 1 & \\
\hline 9. Income & $-.106^{*}$ & .028 & $-.413^{* *}$ & $.171 * *$ & $.221 * *$ & $.098 *$ & .065 & $.224 * *$ & 1 \\
\hline
\end{tabular}

$* p<.05, * * p<.01$

In addition to examining the relationship between self-reported intimate partner violence and demographic characteristics among all participants, the sample was narrowed to just participants who had indicated they had experienced intimate partner violence and the five related interpersonal violence variables. Among those who indicated they had experienced IPV, several notable relationships were found among variables related to IPV. There was a significant, negative relationship between experiencing IPV in the past year and self-sufficiency $\left(\mathrm{r}_{s}=-.182, \mathrm{p} .<.01\right.$; See Table 5). This finding 
indicates those who experienced IPV in the past year were less likely to be self- sufficient. Participants who reported having experienced a physical injury from an intimate partner were also significantly more likely to have trouble working due to IPV $\left(\mathrm{r}_{s}=.407, p<.001\right)$. Findings also indicated that white participants, as compared to their non-white counterparts, were significantly more likely to have trouble working due to IPV $\left(\mathrm{r}_{s}-.268, p .<001\right)$. Moreover, white participants who had experienced IPV were also significantly less likely to be employed full-time $\left(\mathrm{r}_{s}=.164, p<.05\right)$. Lastly, among participants who had experienced IPV, there was a significant relationship between experiencing violence in the last year and the participant perpetrating violence $\left(\mathrm{r}_{s}=.305, p .<.01\right)$.

Table 5. Correlation Matrix for Intimate Partner Violence Sample with Self-Sufficiency as the Dependent Variable

\begin{tabular}{|c|c|c|c|c|c|c|c|c|c|}
\hline & 1 & 2 & 3 & 4 & 5 & 6 & 7 & 8 & 9 \\
\hline $\begin{array}{l}1 . \\
\text { Self-Sufficiency }\end{array}$ & 1 & & & & & & & & \\
\hline $\begin{array}{l}\text { 2. Violence in } \\
\text { Past Year }\end{array}$ & $-.182 * *$ & 1 & & & & & & & \\
\hline $\begin{array}{l}\text { 3. Trouble } \\
\text { Working Due to } \\
\text { DV }\end{array}$ & -.037 & .107 & 1 & & & & & & \\
\hline $\begin{array}{l}\text { 4. Physically } \\
\text { Injured }\end{array}$ & -.008 & .078 & $.407 * *$ & 1 & & & & & \\
\hline $\begin{array}{l}\text { 5. Part. Physically } \\
\text { Violent }\end{array}$ & .002 & .095 & .076 & .049 & 1 & & & & \\
\hline $\begin{array}{l}\text { 6. Part. Physically } \\
\text { Violent Past Year }\end{array}$ & -.032 & $.305^{* *}$ & .070 & .078 & $.375^{* *}$ & 1 & & & \\
\hline $\begin{array}{l}\text { 7. Employment } \\
\text { Status }\end{array}$ & $.251 * *$ & -.133 & -.016 & -.099 & -.050 & -.085 & 1 & & \\
\hline 8. Sanctioned & -.094 & .109 & -.110 & -.131 & -.044 & -.042 & -.106 & 1 & \\
\hline 9. Race & .023 & .073 & $-.268 * *$ & -.128 & -.078 & .104 & $.164 *$ & .108 & 1 \\
\hline
\end{tabular}

\section{Discussion}

The current study examined self-reported intimate partner violence, employment and self-reported self-sufficiency among a sample of TANF economic assistance recipients. Findings from the current study indicate that the overall sample is similar to other studies (Tolman \& Raphael, 2000) in terms of major demographic characteristics such as gender, race, age and number of children. As expected, participants in the current study who reported experiencing physical violence were significantly more likely to be younger in age, non-white, less educated, have fewer children, and under or unemployed.

Overall, response to the mailed survey was successful and exceeded expectations based on the extant literature. The single mail out response rate was over $25 \%$ with only a $6 \%$ return rate for undeliverable mail. This is contrary to previous research and practice-based knowledge that indicates individuals participating in state economic assistance programs are an extremely mobile population that is difficult to reach once they exit these programs. This particular finding suggests two possibilities: a) this population is not nearly as mobile as convention would indicate or b) response rates are dependent upon who is asking for information. Specifically, the surveys for the current study came from a well-known University with no physical ties to the state run economic assistance program. It is possible that program participants are more likely to participate in a mail survey conducted by an outside evaluator.

Major findings of the study indicate that there was a significant, albeit weak, relationship between physical violence and self-sufficiency. Further, survey respondents who reported experiencing IPV within the past year were less likely to consider themselves as self-sufficient. Not surprisingly, respondents who reported an injury resulting from IPV within the last year were also significantly more likely to have trouble working. For the population of women who had experienced IPV within the last year, white women were more likely to report having trouble working as a result of IPV and were less likely to be employed full-time than women of other races. These findings highlight intimate partner violence as a barrier both to work and to continued employment, particularly for women with recent experiences of IPV.

While just over one-third (35.5\% of respondents reporting IPV within the past year) of the survey sample reported that they were self-sufficient, fewer than half of the survey respondents indicated that participation in the TANF program assisted them in securing employment that allowed them to be self-sufficient. This finding indicates the need for more research to better understand how TANF participants, particularly those who have experienced or are experiencing IPV, define self-sufficiency. As discussed in the literature, and as indicated by the number of participants who defined themselves as self-sufficient (even with incomes under \$5,000), self-sufficiency appears to mean much more than economic stability to participants. Future research should further explore the dimensions of self-sufficiency among this particular population. 
Another notable finding indicates that individuals who are sanctioned while in the program are more likely to be unemployed or seeking employment. Also, older participants were significantly more likely to be sanctioned while in the program. The application of sanctions for non-compliance in state run economic assistance programs appears to be an ongoing barrier to employment. The sanctions process, by nature, is circular. For example, women who report dealing with IPV are less likely to be employed but are in need of cash assistance to remove themselves from their current living situation (Cheng, 2002; Cheng, 2012). State run TANF economic assistance programs require an individual to be looking for work, volunteering, or working part time (Center on Budget and Policy Priorities, 2015) for both eligibility and compliance with program rules. Participants who are not meeting these requirements are sanctioned, which in turn further limits both the job hunting process and the ability to acquire quality childcare. If women who have experienced, or are experiencing, IPV encounter more absenteeism, harassment at work, and more issues with consistent childcare, they are also likely to be disproportionately sanctioned due to not fulfilling program requirements (Tolman \& Raphael, 2000). As such, this particular issue warrants further exploration to fully understand the reasons participants are being sanctioned to fully address this issue.

Although the relationship between intimate partner violence and unemployment / underemployment are well documented, these findings represent a more tangible direction for future study as well as contribute to the literature of the complexities of employment for women who experience IPV. One of the main goals of the TANF cash assistance program is to assist participants in becoming self-sufficient. Holistically addressing the barriers found in the research such as childcare, safe housing plans, and detailed case action plans for victims of IPV and modifying the program appropriately has the potential to increase participant employment, but also self-sufficiency for women who are victims of IPV. Acknowledging the role of intimate partner violence in TANF program success for participants is essenti al to overall program success.

\subsection{Limitations}

The current study had several notable limitations. The sample for the study was relatively small, with just one-third of the original sample indicating that they had been, or were currently, in a relationship in which intimate partner violence was an issue. The findings may not be generalizable as the sample was taken from one small state in the southern U.S. Moreover, data analysis was limited to the way in which the survey information was collected, specifically at the nominal and ordinal levels of measurement which precludes more robust statistical te sting as well as more in-depth, qualitative analysis of the participant's particular situation.

Additionally, although self-report is reasonably reliable, in the context of intimate partner violence, reporting abuse may be rather low, especially if the victim is still living in the home with their abuser. As such, the number of participants who disclosed intimate partner violence may be only a fraction of the actual number of women experiencing intimate partner violence in their homes. Women experiencing IPV may not disclose violence even on an anonymous survey for fear of the abusive partner seeing their responses, or they may simply not identify the violence for reasons of shame, cultural norms, or a desire for privacy. Furthermore, the questions used to ascertain IPV frequency were not inclusive of psychological violence or other controlling behavior invoked by the partner, issues that are also known to affect employment.

Lastly, self-sufficiency was not defined for the participant. Instead it was left to the participant to define as they saw fit. As such, it is not fully understood what made an individual indicate that they were self-sufficient. Definitions of self-sufficiency likely vary widely by participant and their general idea of self-sufficiency may be limited by their individual experiences. The most notable example of this would be the number of participants who considered themselves self-sufficient while also disclosing their income to be anywhere from under $\$ 5,000-\$ 20,000$ per year. This would seem to indicate that the definition of self-sufficiency is not based on income alone. More complex mechanisms appeared to be underrepresented with regard to individual resilience, empowerment, and personal self-sufficiency.

\subsection{Implications for Policy and Practice}

Findings from the current study indicated that the participants who self-reported intimate partner violence in the last year also felt that the TANF economic assistance program did not support their efforts in becoming self-sufficient. This may indicate that TANF participants are not receiving adequate skill building and job training before attempting to leave the program for employment (Cheng, 2012). Further, TANF recipients who do not gain employable skill sets while in the program may be more likely to have to reenter the program due to unemployment. Because intimate partner violence is negatively associated with level of education, age, and full-time employment, TANF recipients who are abused by an intimate partner may be even more likely to cycle through the system (Cheng, 2012). Therefore, case managers and social workers aiding this particular population should be better educated and trained not only on the effects of intimate partner violence, but also on best practices for addressing barriers and creating more successful outcomes for this population.

Although this study focused on economic self-sufficiency, the correlation of IPV and the inability of the TANF program to contribute to perceived self-sufficiency indicates a need for more research on additional facets of self-sufficiency that 
may be hindered by IPV. The interdimensional complexity of multiple barriers to self-sufficiency are especially important for both practitioners and researchers to understand, as these barriers require both micro-level interventions, and macro-level advocacy at the agency and legislative level. Incorporating a multi-system life course perspective of self-sufficiency for survivors of IPV provides a deeper understanding of the life experiences that impede economic independence (Murphy-Erby et al., 2010). Successful interventions must be developed through a lens that recognizes and values the worldview of the individual along with recognition of human agency and the complex social systems within which IPV occurs. Holistically addressing the multiple barriers to self-sufficiency for IPV survi vors may not only create long-term employment options for survivors of intimate partner violence, but may also reduce costs of state TANF economic assistance programs and mental health treatment for employers and communities.

\section{Conclusion}

TANF recipients who are physically abused by an intimate partner fare worse on a number of measures of self-sufficiency than do recipients who report no abuse. Although intimate partner violence is just one of many barriers to self-sufficiency for poor women, the lack of access to employment has dire consequences for women reliant upon TANF economic benefits. The current study clearly indicates a need to further explore the linkages between intimate partner violence, especially current and ongoing violence, access to employment, and other barriers to self-sufficiency for TANF recipients.

\section{Acknowledgements}

We would like to thank our University of Arkansas at Little Rock colleagues who made significant contributions to creating measurement tools and collecting and entering data. We would also like to acknowledge and dedicate this manuscript to Cody Cheek, who spent many years working through the literature and data. We sincerely appreciate his efforts on this manuscript and miss him very much.

\section{References}

Armour, C., \& Sleath, E. (2014). Assessing the co-occurrence of intimate partner violence domains across the life course: Relating typologies to mental health. European Journal of Psychotraumatology, 5. https://doi.org/10.3402/ejpt.v5.24620

Benson, M. L., Fox, G. L., DeMaris, A., \& Van Wyk, J. (2003). Neighborhood disadvantage, indi vidual economic distress and violence against women in intimate relationships. Journal of Quantitative Criminology, 19, 207-235. https://doi.org/10.1023/A:1024930208331

Benson, M., Wooldredge, J., Thistlethwaite, A., \& Fox, G. (2004). The correlation between race and domestic violence is confounded with community context. Social problems, 51,326-342. https://doi.org/10.1525/sp.2004.51.3.326

Bonomi, A. E., Anderson, M. L., Rivara, F. P., \& Thompson, R. S. (2007). Health outcomes in women with physical and sexual intimate partner violence exposure. Journal of Women's Health, 16, 987-997. https://doi.org/10.1089/jwh.2006.0239

Bowie, S. L., \& Dopwell, D. M. (2013). Metastressors as barriers to self-sufficiency among TANF-reliant African American and Latina Women. Affilia, 28, 177-193. https://doi.org/10.1177/0886109913484693

Brownell, P. (1998). Women, welfare, work, and domestic violence. In A. R. Roberts (Ed.), Battered women and their families (pp. 291-309). New York: Springer Publishing Co., Inc.

Butler, S. S., Corbett, J., Bond, C., \& Hastedt, C. (2008). Long-Term TANF Participants and barriers to employment: A qualitative study in Maine. Journal of Sociology \& Social Welfare, 35, 49-69.

Cancian, M., Meyer, D., \& Caspar, E. (2008). Welfare and Child Support: Complements, Not Substitutes. Journal of Policy Analysis and Management, 27,354-375. https://doi.org/10.1002/pam.20328

Catalano, S. (2013). Intimate partner violence: Attributes of Victimization, 1993-2011. U.S. Department of Justice, Office of Justice Programs.

Center on Budget and Policy Priorities (2015). Policy Basics: An Introduction to TANF. Retrieved from https://www.cbpp.org/research/policy-basics-an-introduction-to-tanf

Cheng, T. (2012). Intimate partner violence and welfare participation: A Longitudinal Causal Analysis. Journal of Interpersonal Violence, $28,808-830$. https://doi.org/10.1177/0886260512455863

Chun-Chung Chow, J., Jaffee, K., \& Snowden, L. (2003). Racial/ethnic disparities in the use of mental health services in poverty areas. Research and Practice, 93, 792-797.

Cole, P. (2000). Welfare and domestic violence: Federal and state laws and policies. National Center on Domestic and 
Sexual Violence. Retrieved from: www.ncadsv.org

Cronholm, P., Forke, C., Wade, R., Bair-Merritt, M., Davis, M., Harkins-Schwarz, M., ... Fein, J. (2015). Adverse childhood experiences: Expanding the concept of adversity. American Journal of Preventative Medicine, 49, 354-361. https://doi.org/10.1016/j.amepre.2015.02.001

Dillman, D. A., Smyth, J. D., \& Christian, L. M. (2009). Internet, mail, and mixed-mode surveys: The tailored design method (3rd ed.). New York, NY: John Wiley \& Sons

Falk, G. (2016). The Temporary Assistance for Needy Families (TANF) block grant: Responses to frequently asked questions (CRS Report R32760). Washington, DC: Congressional Research Service.

Goodman, L. A., Smyth, K. F., Borges, A. M., \& Singer, R. (2009). When crises collide: how intimate partner violence and poverty intersect to shape women's mental health and coping? Trauma, Violence, \& Abuse, 10, 306-329. https://doi.org/10.1177/1524838009339754

Hong, P. Y., Polanin, J., \& Pigott, T. (2012). Validation of the Employment Hope Scale: Measuring psychological self-sufficiency among low-income jobseekers. Research on Social Work Practice, 22, 323-332. https://doi.org/10.1177/1049731511435952

Hong, P. Y., Sheriff, V., \& Naeger, R. (2009). A bottom-up definition of self-sufficiency: Voices from low-income job seekers. Qualitative Social Work, 8,357-376. https://doi.org/10.1177/1473325009337844

Kimerling, R., Alvarez, J., Pavao, J., Mack, K. P., Smith, M. W., \& Baumrind, N. (2009). Unemployment among women examining the relationship of physical and psychological intimate partner violence and posttraumatic stress disorder. Journal of Interpersonal Violence, 24, 450-463. https://doi.org/10.1177/0886260508317191

Lindhorst, T., \& Tajima, E. (2008). Reconceptualizing and operationalizing context in survey research on intimate partner violence. Journal of Interpersonal Violence, 23, 362-388. https://doi.org/10.1177/0886260507312293

Murphy-Erby, Y., Christy-McMullin, K., Strauss, K., \& Schriver, J. (2010). Multi-systems life course: A new practice perspective and its application in advanced practice with racial and ethnic populations. Journal of Human Behavior in the Social Environment, 20, 672-687. https://doi.org/10.1080/10911351003751868

National Center for Injury Prevention and Control. (2003). Costs of intimate partner violence against women in the United States. Atlanta (GA): Centers for Disease Control and Prevention.

Pearson, J., Griswold, E., \& Thoennes, N. (2001). Balancing safety and self-sufficiency: Lessons on serving victims of domestic violence for child support and public assistance agencies. Violence Against Women, 7, 176-192. https://doi.org/10.1177/10778010122182389

Pilkinton, M. (2010). TANF Recipients' barriers to employability: Substance abuse and domestic violence. Journal of Human Behavior in the Social Environment, 20, 1011-1023. https://doi.org/10.1080/10911359.2010.494940

Pompa, L. (2007). The family violence option in Texas: Why it is failing to aid domestic violence victims on welfare and what to do about IT. Texas Journal of Women and the Law, 16, 241-259.

Postmus, J. L. (2004). Battered and on welfare: The experiences of women with the Family Violence Option. Journal of Sociology and Social Welfare, XXXI, 113-123.

Renzetti, C. (2009). Editor's Introduction. Violence Against Women, 15, 1271-1272. https://doi.org/10.1177/1077801209348777

Riger, S., \& Staggs, S. (2004). Welfare reform, domestic violence, and employment. Violence Against Women, 10, 961-990. https://doi.org/10.1177/1077801204267464

Riger, S., Staggs, S., \& Schewe, P. (2004). Intimate partner violence as an obstacle to employment among mothers affected by welfare reform. Journal of Social Issues, 60, 801-818. https://doi.org/10.1111/j.0022-4537.2004.00387.x

Smith, C., Ireland, T., Park, A., Elwyn, L. \& Thornberry, T. (2011). Intergenerational continuities and discontinuities in intimate partner violence: A two-generational prospective study. Journal of Interpersonal Violence, 26. https://doi.org/10.1177/0886260511403751

Tolman, R. M., \& Raphael, J. (2000). Areview of research on welfare and domestic violence. Journal of Social Issues, 56, 655-682. https://doi.org/10.1111/0022-4537.00190

Wallace, R. (2015). Domestic violence and intimate partner violence: What's the difference? Public Safety. Retrieved from: http://inpublicsafety.com/2015/10/domestic-violence-and-intimate-partner-violence-whats-the-difference/

Wetterson, K., Rudolph, S., Faul, K., Gallagher, K., Transgrud, H., Adams, K., Graham, S., \& Terrance, C. (2004). 
Freedom through self-sufficiency: Aqualitative examination of the impact of domestic violence on the working lives of women in a shelter. Journal of Counseling Psychology, 51, 447-462. https://doi.org/10.1037/0022-0167.51.4.447

World Health Organization. (2012). Understanding and addressing violence against women. Retrieved from: http://apps.who.int/iris/bitstream/10665/77432/1/WHO_RHR_12.36_eng.pdf

Zinzow, H., Ruggiero, K., Resnick, H., Hanson, R., Smith, D., Saunders, B., \& Kilpatrick, D. (2009). Prevalence and mental health correlates of witnessed parental and community violence in a national sample of adolescents. Journal of Child Psychology and Psychiatry, 50, 441-450. https://doi.org/10.1111/j.1469-7610.2008.02004.x

\section{Notes}

Note 1 . The consent procedures and human subjects protocol were approved by the University Institutional Review Board.

\section{Copyrights}

Copyright for this article is retained by the author(s), with first publication rights granted to the journal.

This is an open-access article distributed under the terms and conditions of the Creative Commons Attribution license which permits unrestricted use, distribution, and reproduction in any medium, provided the original work is properly cited. 